Article

\title{
Control of Variable Speed Wind Turbines with Doubly Fed Asynchronous Generators for Stand-Alone Applications
}

\author{
Santiago Arnaltes $\mathbb{B}^{\mathbb{D}}$, Jose Luis Rodriguez-Amenedo and Miguel E. Montilla-DJesus * \\ Electrical Engineering Department, Carlos III University of Madrid, Av. de la Universidad 30, Leganés, \\ 28911 Madrid, Spain; arnalte@ing.uc3m.es (S.A.); amenedo@ing.uc3m.es (J.L.R.-A.) \\ * Correspondence: mmontill@ing.uc3m.es; Tel.: +34-916-24-5992
}

Received: 14 November 2017; Accepted: 21 December 2017; Published: 23 December 2017

\begin{abstract}
This paper addresses the design and implementation of a novel control of a variable speed wind turbine with doubly fed induction generator for stand-alone applications. In opposition to grid-tied applications, in stand-alone systems the voltage and frequency must be generated by the doubly fed induction generator. Therefore, a voltage and frequency controller is required for supplying the load at constant voltage and frequency. This controller is implemented by orientation of the generator stator flux vector along a synchronous reference axis. In this way, constant voltage and frequency is obtained and the generator will supply the active and reactive power demanded by the load, while the wind turbine will be responsible for achieving power balance in the system. Then, power control is assumed by the pitch actuator controlling the rotational speed of the wind turbine for power balancing. A load shedding mechanism is needed if the load power exceeds the maximum available wind power. Detailed simulation results are presented and discussed to demonstrate the capabilities and contributions of the proposed control scheme.
\end{abstract}

Keywords: Doubly-fed induction generator (DFIG); wind turbine; power control; frequency control

\section{Introduction}

Traditionally, wind farms have been operated to extract maximum energy yield, assuming certain conditions of voltage and frequency in the grid without contributing to its support [1]. So far, wind power plants are not connected massively in weak networks, and even less in isolated systems. However, recent innovations in micro-grids have aroused the interest in the standalone operation of the wind turbine (WT), as part of isolated grids, or as distributed generators in weak networks [2-4]. Another interesting area of application is in offshore wind farms connected to grid through an high-voltage direct current (HVdc) link. In these systems, the offshore wind farm is isolated from the grid. While in voltage-sourced converter (VSC)-HVdc technology the wind farm voltage is supplied by the VSC rectifier, if a line-commutated converter (LCC)-HVdc rectifier is employed the voltage must be generated by the wind turbine generators, which are now operating in the isolated grid of the wind farm feeding the LCC rectifier [5,6].

Unlike in grid-connected systems, WT in stand-alone and islanding operation must impose and maintain voltage and frequency while matching generation and load, despite of varying rotor speed due to wind speed variations and varying loads. When generation exceeds demanded load, generation must be reduced by controlling the pitch angle of blades. On the other hand, if generation is not enough to supply the load, a load shedding mechanism must be employed [7]. Thus, standalone operation requirements imply that WT must have active power control through aerodynamic control and power electronic converters control $[8,9]$. WT technologies that meet these requirements are those based on variable speed generators and pitch control. Among these technologies, the doubly fed 
induction generator (DFIG) arises as an attractive option, as this is the dominant technology in the market nowadays [10-13].

The grid-tied control of the DFIG has been extensively treated in literature. [14] presents an overview of control systems for DFIG, which includes a large amount of references. Nevertheless, the stand-alone operation of DFIG-based wind turbines has not been investigated much in the literature. In [15] the control of a DFIG supplying an isolated load is presented. In this paper an indirect stator-oriented vector control scheme is used to provide constant voltage and frequency for variations in both load and wind speed. Further studies on this topic when the DFIG is connected to an unbalanced load using sensorless control have been published by the same authors in [16], and more recently by other authors in [17]. A similar indirect control approach is proposed in [18], but using rotor flux control instead of rotor current.

In [19] a direct voltage control for a stand-alone DFIG is presented. This proposal uses the polar coordinates of the stator voltage vector for controlling the voltage magnitude and frequency. The proposed technique employs the rotor current magnitude and frequency to control the stator voltage magnitude and frequency, respectively. The same approach has also been proposed in $[20,21]$.

This paper presents a new control strategy to regulate the voltage and frequency of the DFIG in stand-alone operation. While in [15] indirect control is used for flux orientation, here flux orientation is achieved by direct control of the flux angle in a very reliable and robust way. A direct voltage and frequency controller (DVFC) is used to maintain constant voltage and frequency during stand-alone operation. Voltage and frequency control is based on the orientation of the stator flux vector along a synchronous axis rotating at the reference synchronous speed. The ability of the DVFC to maintain the stator flux oriented toward the synchronous reference axis means that constant voltage and frequency is obtained, which in turn it means that the load active and reactive power is supplied by the DFIG.

Another important improvement is that while in [15] a dummy load is used to match the load power and the WT power following the maximum power point tracking (MPPT) strategy, here the WT power control (WTPC) assures that the WT produces just the power demanded by the load. The DVFC implies a load tracking strategy where the DFIG torque is imposed by the load. Therefore, this affects the rotational speed of the WT which in turn is controlled by the blade pitch actuator. By controlling the rotational speed, the power drawn from the WT is equal to the generator power and in turn to the load power.

Simulation results in a 2 MW WT are presented and discussed to demonstrate the capabilities of the proposed control scheme for stand-alone operation.

The paper is organized as follows. In Section 2, first the overall system is presented, and the WT and DFIG models are introduced, from which the proposed control scheme is obtained in Section 3. In Section 4 , simulation results are presented and discussed and finally conclusions are established in Section 5 .

\section{Stand-Alone DFIG Based Variable Speed Wind Turbine}

The DFIG-based wind turbine configuration for stand-alone operation is shown in Figure 1. It consists of a variable speed wind turbine coupled to a wound rotor induction generator with its stator directly connected to the load and its rotor connected through a back-to-back converter.

In this configuration, the control system has two main components: the DVFC responsible for obtaining constant voltage and frequency at the generator terminals, and the WT power controller responsible for balancing power through the system. On the other hand, the operation of the DFIG also requires the control of the grid side converter, but this is done as conventional and therefore it is not going to be presented through the paper, as it is based on the well-known control of the DC link voltage for injecting the rotor power to the line [22]. The main difference here is that the line voltage must be created first by generator stator. Also, a load shedding controller is necessary for regulating the load when it is higher than the available wind power. 


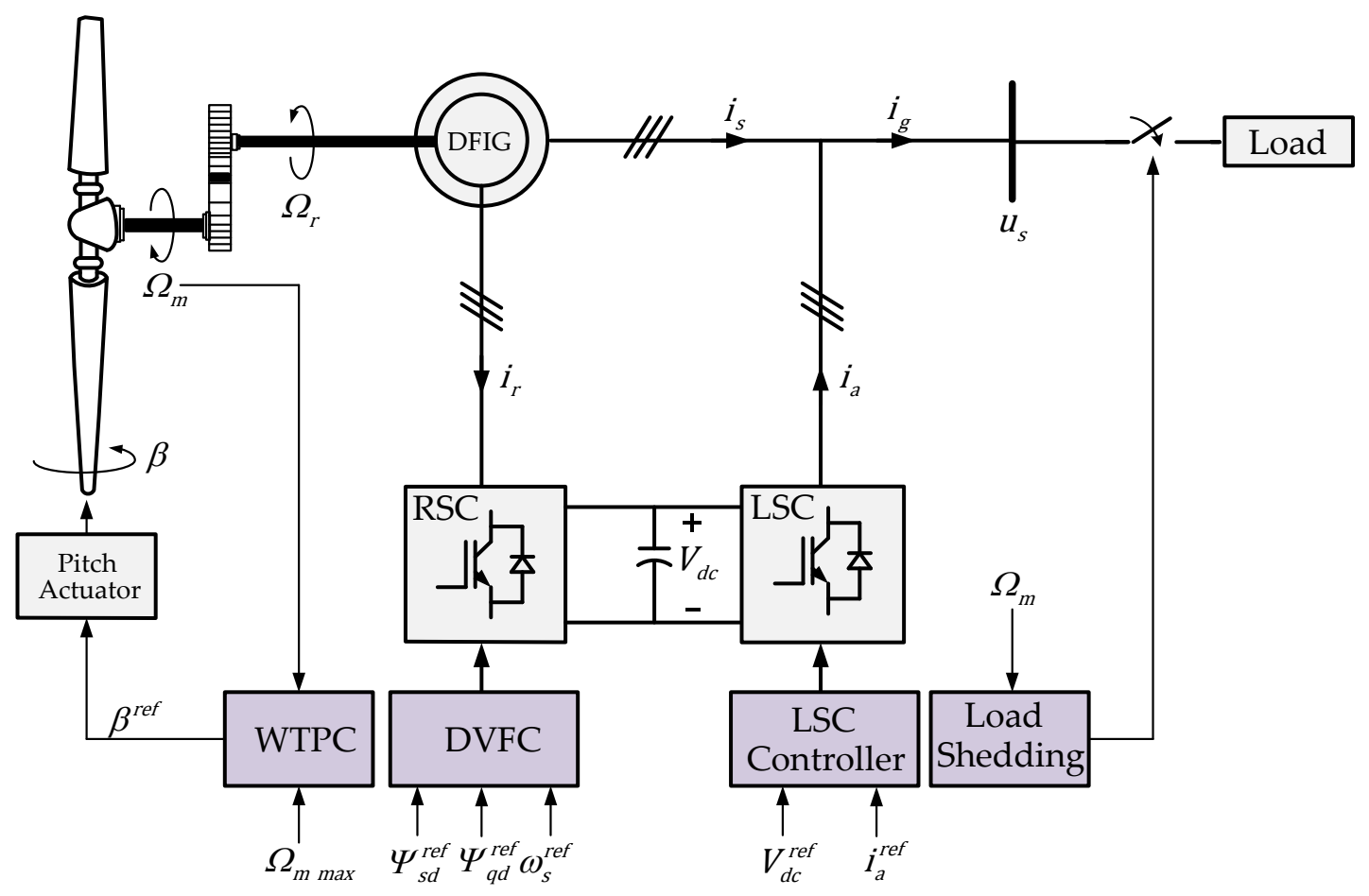

Figure 1. Schematic diagram of the Stand-Alone doubly-fed induction generator (DFIG).

Finally, it has to be remarked again that the stator angular frequency, $\omega_{s}$, of the DFIG in stand-alone operation is obtained from a control reference and not from the grid by a phase-locked loop (PLL), as in grid-connected operation. This is the angular frequency of the synchronous reference frame where the stator flux vector will be aligned by control, as presented in Section 3.

\subsection{Wind Turbine Model}

The simple and well-known one-mass mechanical model [22] is proposed to study the dynamics of the mechanical system and to derive the stability of the system.

$$
T_{m}-T_{g}=J \frac{d \Omega_{m}}{d t}+D \Omega_{m}
$$

where $\Omega_{m}$ is the wind turbine rotational speed, $T_{m}$ and $T_{g}$ are the wind turbine and the generator torque, respectively, and $J$ and $D$ are the inertia moment and friction coefficient, respectively.

The wind turbine model provides the turbine mechanical torque, $T_{m}$, based on the well-known steady-state power characteristics of the wind turbine [10,22]. The mechanical power, $P_{m}$, of the wind turbine is given by:

$$
P_{m}=\frac{1}{2} \rho A v^{3} C_{p}(\lambda, \beta)
$$

where $\rho$ is the air density; $C_{p}$ is the performance coefficient of the wind turbine which is a function of the tip speed ratio, $\lambda$, and the blade pitch angle, $\beta$. In this model, the wind speed $v$ represents the mean value of the upstream wind and $A$ is the area swept by the turbine blades.

Therefore, the WT torque can be expressed as follows:

$$
T_{m}=\frac{P_{m}}{\Omega_{m}}
$$

The function $C_{p}(\lambda, \beta)$ in (2) has been modeled by using the equation proposed in [23]. The maximum power point is obtained at $C_{p \max }=0.48$, with optimum tip speed ratio $\lambda_{B}=8.1$, and for a 
minimum blade pitch angle $\beta_{\min }=0$. Figure 2 shows the WT power characteristics, for various wind speed values as a function of the rotational speed.

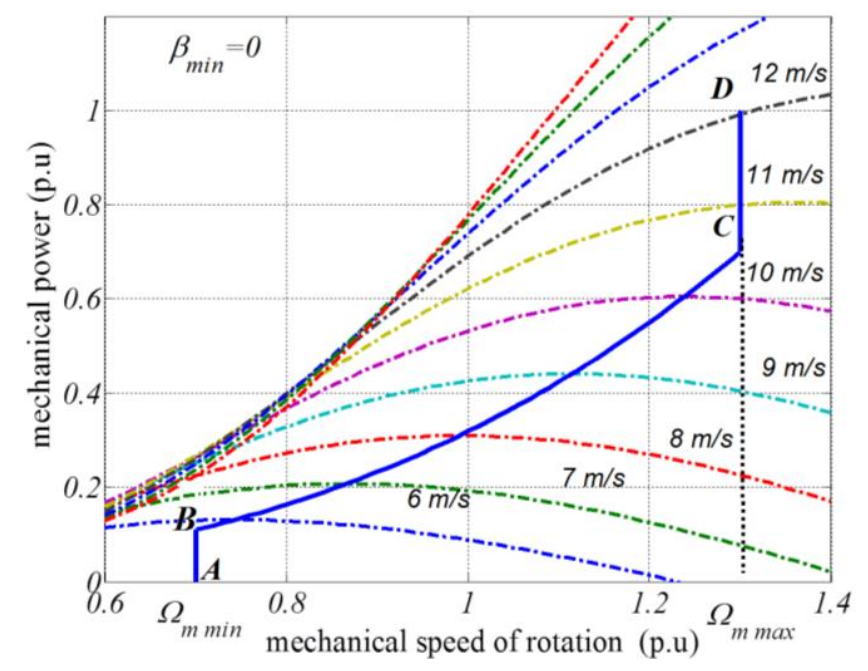

Figure 2. Wind turbine power characteristic DFIG $\left(P_{m}\right.$ vs. $\left.\Omega_{m}\right)$.

As will be shown in Section 3, maximum power locus (curve $B-C-D$ ) is particularly relevant because it defines the stability limit of the WT supplying an isolated load. This curve will be used in the control strategy of the WT to obtain the maximum active power that the generator can produce that guarantees a stable operation. The wind speed at point $C$, where maximum mechanical rotational speed, $\Omega_{m}$ max , is achieved, is also important, and it is defined as the base wind speed, $v_{B}$, as follows.

$$
v_{B}=\frac{\Omega_{m \max } R}{\lambda_{B}}
$$

where $R$ is the turbine radius.

On the other hand, in a WT with active power control, the blade pitch angle $\beta$ is controlled by a pitch servo mechanism [10,22]. The WT power control (WTPC, see Section 3.3) produces a blade angle set-point $\beta^{\text {ref }}$, followed by means of the pitch servo mechanism, turning the WT blades to control the mechanical power output.

\subsection{DFIG Model}

The DFIG stator and rotor voltage vector equations in a synchronous reference frame $\omega_{s}[10,22]$ are defined as:

$$
\begin{aligned}
& -\mathbf{u}_{\mathbf{s}}=R_{s} \mathbf{i}_{\mathbf{s}}+\frac{d \boldsymbol{\psi}_{\mathbf{s}}}{d t}+j \omega_{s} \boldsymbol{\psi}_{\mathbf{s}} \\
& -\mathbf{u}_{\mathbf{r}}=R_{r} \mathbf{i}_{\mathbf{r}}+\frac{d \boldsymbol{\psi}_{\mathbf{r}}}{d t}+j s \omega_{s} \boldsymbol{\psi}_{\mathbf{r}}
\end{aligned}
$$

Being the stator and rotor flux linkages in the synchronous reference frame expressed as

$$
\begin{aligned}
& \boldsymbol{\psi}_{\mathbf{s}}=L_{s} \mathbf{i}_{\mathbf{s}}+L_{m} \mathbf{i}_{\mathbf{r}} \\
& \boldsymbol{\psi}_{\mathbf{r}}=L_{m} \mathbf{i}_{\mathbf{s}}+L_{r} \mathbf{i}_{\mathbf{r}},
\end{aligned}
$$

The electromagnetic torque can be expressed using the d-q components as follow:

$$
T_{g}=\frac{3}{2} p \frac{L_{m}}{L_{s}}\left(i_{r d} \psi_{s q}-i_{r q} \psi_{s d}\right)
$$


where $\mathbf{u}_{s}, \mathbf{u}_{r}, \mathbf{i}_{s}, \mathbf{i}_{r}, \psi_{s}, \psi_{r}$ are the space phasor of the stator and rotor voltages, currents and fluxes, respectively, and $L_{s}, L_{r}$ and $L_{m}$ are the stator, rotor and mutual inductance, respectively; $R_{s}$ and $R_{r}$ are the stator and rotor resistances, respectively; $\omega_{s}$ the stator angular frequency; $s$ is the slip; and $p$ is number of pole pairs.

\section{System Control and Operation}

The objective of the control system of a DFIG-based wind turbine operating in stand-alone mode is to maintain constant voltage and frequency at the generator terminals. The starting of the DIFG requires the pre-charge of the DC bus of the back-to-back converters. In grid-connected DFIG this is done from the grid through the line-side converter (LSC). In an islanded DFIG an external voltage source is needed for excitation because it is not possible charging the dc capacitor from the grid through the LSC. For pre-charging the DC bus, a reduced capacity battery system or even a small permanent magnet synchronous generator (PMSG) mechanically coupled to the DFIG shaft can be used, as proposed in [22].

Once the DC bus is pre-charged, the DFIG is controlled through the rotor-side converter (RSC) to obtain nominal voltage and frequency at the generator terminals at not-load. At this moment, the LSC will charge the DC bus at nominal voltage $V_{d c}$ and the exciter is automatically blocked.

\subsection{Direct Voltage and Frequency Control (DVFC)}

The control of the stand-alone DFIG is based on the orientation of the stator flux vector along a synchronous reference frame ( $\mathrm{d}$-axis whose rotational speed is $\omega_{s}^{r e f}=2 \pi \cdot 50 \mathrm{rad} / \mathrm{s}$ ) generated by the controller. As long as the control is able to maintain the stator flux vector orientated along the $\mathrm{d}$-axis, the frequency $(50 \mathrm{~Hz})$ is kept constant. Note that this principle is different from the conventional stator flux oriented control (FOC) employed in grid-tied DFIG [22]. In FOC the quadrature component of the flux is zero by definition, while in this new proposal it is the objective of the control system to make this component zero. Also, while in FOC the quadrature component of the flux zero, the quadrature component of the current is free, and it is used to set torque as desired. In contrast, here the quadrature component of the flux has to be taken to zero, and in order to achieve this, the quadrature component of the current will be used, as demonstrated below, that is, it is not free, as the generator torque cannot be set because it will be forced by the load power.

For such purposes, a DVFC based in the following principle is employed. In steady state, the stator flux vector will be aligned along the d-axis and therefore $\psi_{s d}=\left|\psi_{s}{ }^{r e f}\right|$ and $\psi_{s q}=0$. In order to achieve these references, two control channels are implemented. The first one to obtain constant stator flux and the second one to obtain constant frequency, i.e., $\psi_{s q}=0$ (see Figure 3).

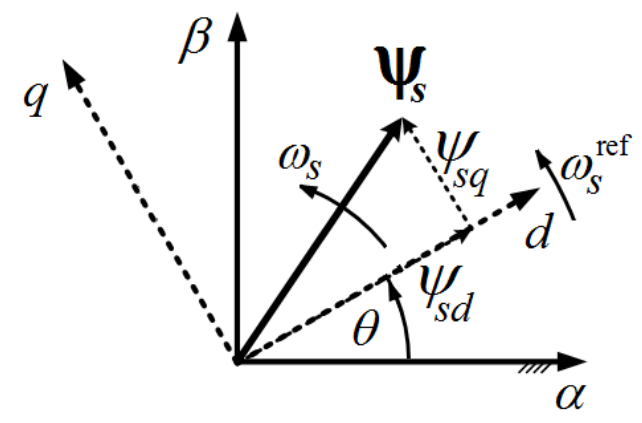

Figure 3. Voltage vector in a synchronous reference frame.

In Figure 4, the reference stator flux is compared to the d-axis component of the actual stator flux vector while the q-axis component of the actual stator flux vector is compared to zero. The reference $\mathrm{d}$-axis is obtained by integration of the desired angular frequency $\omega_{s}^{r e f}$. 


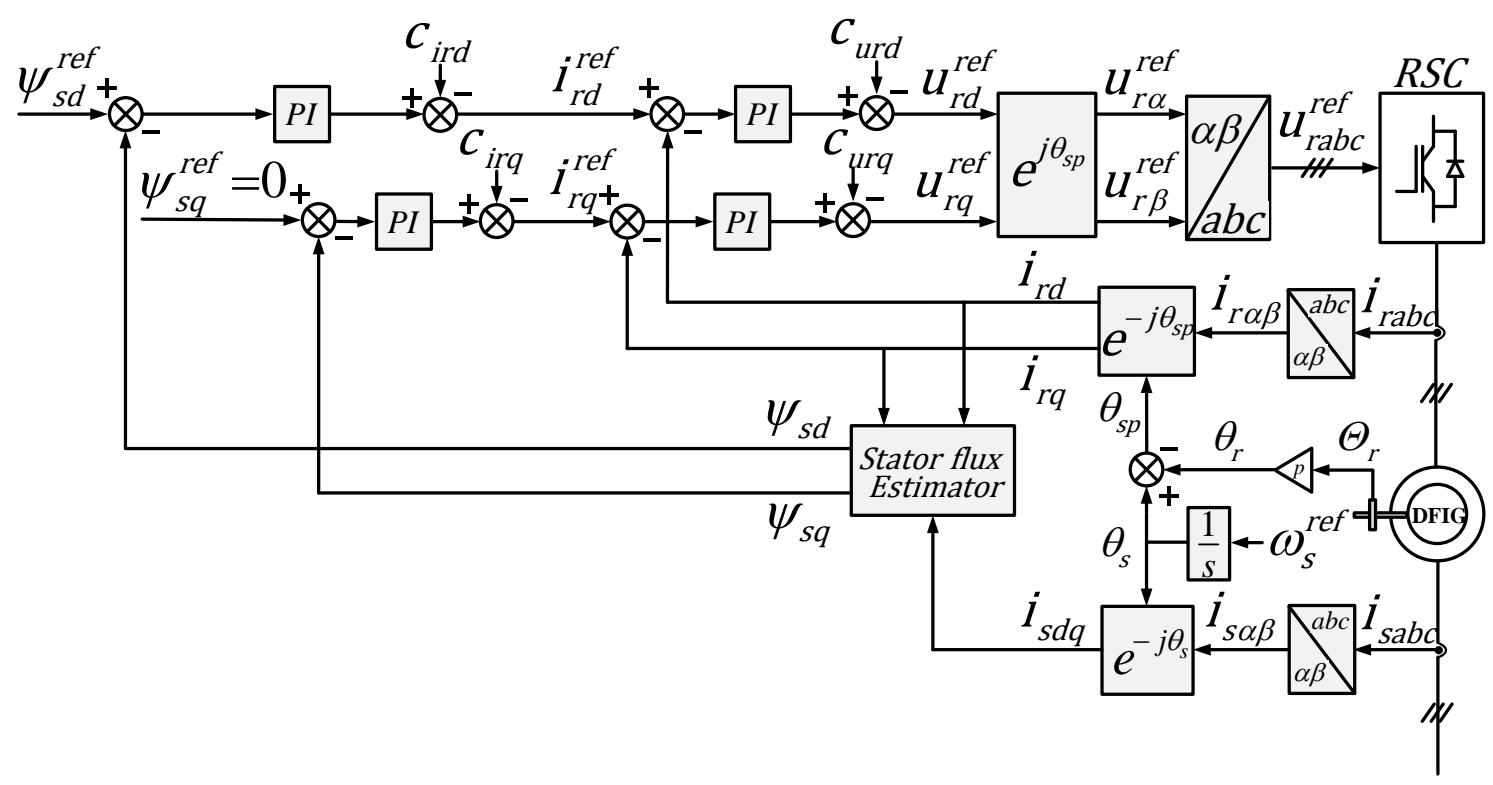

Figure 4. Direct voltage and frequency control (DVFC) for the DFIG stand-alone operation.

Stator flux can be controlled by means of the rotor currents imposed by the RSC. Using (5) and (8) in $\mathrm{d}-\mathrm{q}$ components, the following expressions can be obtained:

$$
\begin{aligned}
& \tau_{s} \frac{d \psi_{s d}}{d t}+\psi_{s d}=+L_{m} \cdot i_{r d} \underbrace{-\tau_{s} \cdot u_{s d}+\omega_{s} \cdot \tau_{s} \cdot \psi_{s q}}_{C_{i r d}}, \\
& \tau_{s} \frac{d \psi_{s q}}{d t}+\psi_{s q}=+L_{m} \cdot i_{r q} \underbrace{-\tau_{s} \cdot u_{s q}+\omega_{s} \cdot \tau_{s} \cdot \psi_{s d}}_{C_{i r q}},
\end{aligned}
$$

where $\tau_{s}=L_{s} / R_{s}$.

These expressions show that $\psi_{s d}$ can be controlled by the d-axis component of the rotor current, $i_{r d}$, while $\psi_{s q}$ can be controlled by the q-axis component of the rotor current, $i_{r q}$. There is also one coupling term in each equation $\left(c_{i r d}\right.$ and $\left.c_{i r q}\right)$ that can be compensated using the corresponding feed-forward terms as is shown in Figure 4.

Finally, two d-q current regulators will impose the desired current components through the d-q component of the rotor voltage, as shown in the following expressions, obtained from (6) and (8):

$$
\begin{gathered}
\sigma \cdot L_{r} \frac{d i_{r d}}{d t}+R_{r} i_{r d}=-u_{r d} \underbrace{-\frac{L_{m}}{L_{s}} \frac{d \psi_{s d}}{d t}+s \omega_{s} \frac{L_{m}}{L_{s}} \cdot \psi_{s q}-s \omega_{s} \sigma L_{r} i_{r q}}_{C_{u r d}}, \\
\sigma \cdot L_{r} \frac{d i_{r q}}{d t}+R_{r} i_{r q}=-u_{r q} \underbrace{-\frac{L_{m}}{L_{s}} \frac{d \psi_{s q}}{d t}-s \omega_{s} \frac{L_{m}}{L_{s}} \cdot \psi_{s d}-s \omega_{s} \sigma L_{r} i_{r d}}_{C_{u r q}},
\end{gathered}
$$

where $\sigma=1-L_{m}^{2} /\left(L_{s} L_{r}\right)$ and $c_{u r d}$, and $c_{u r q}$ are also feed-forward compensation terms in the current control loops.

Figure 4 shows the complete voltage and frequency control (DVFC) scheme for the DFIG in stand-alone operation.

On the other hand, a stator flux estimator based on (7) is used for feeding-back the actual stator flux components, which requires the rotor and stator current measurements. 
Also, note that because the whole control is oriented to a synchronous axis obtained directly by integration of the desired angular frequency $\left(\omega_{s}^{r e f}\right)$, this signal is not subjected to any measurement noise or grid disturbance, which would be the case if a PLL was needed.

Another important consideration is that with controlled stator flux, the voltage deviation due to the load current is only due to the voltage drop in the stator resistance, as given by (5), which it is usually very small (between 0.005 and 0.02 p.u., depending on the generator rating). This means that the proposed DVFC does not require a voltage regulator to maintain voltage within acceptable margins.

\subsection{Line Side Converter (LSC) Control}

The line side converter is used for controlling the back-to-back converters DC voltage, as in grid-tied DFIG. By doing this, the control automatically assures that the rotor power is instantaneously transferred to the grid [22]. Moreover, the decoupled control of the LSC active and reactive current also allows for the adjustment of the LSC reactive current, that here it is set to zero following a minimum current strategy.

\subsection{Wind Turbine Power Control (WTPC)}

In the previous section, it has been shown how the DVFC will supply constant voltage and frequency to the load, being the generator power equal to the load power. Nevertheless, in steady state, power balance can only be achieved if the WT supplies to the generator exactly the active power demanded by the load (obviously, adding mechanical, magnetic and electric losses). In order to do so a WT power control (WTPC) is required.

From (1), neglecting the rotational losses for the sake of simplicity, in steady state the WT driving torque $T_{m}$ must equal the braking torque of the generator $T_{g}$, or, by multiplying by the rotational speed $\left(\Omega_{m}\right)$, the WT power $P_{m}$ equals the generator power $P_{g}$. On the other hand, if $P_{g}$ is equal to the load power, $P_{l}$, the former relationship implies that if $P_{m}$ is higher than $P_{l}, \Omega_{m}$ will increase, or decrease if $P_{m}$ is lower than $P_{l}$. Therefore, power balance can be achieved by means of a speed control loop: only when $P_{m}=P_{l}, \Omega_{m}$ is kept constant. This speed control loop is shown in the Figure 5 .

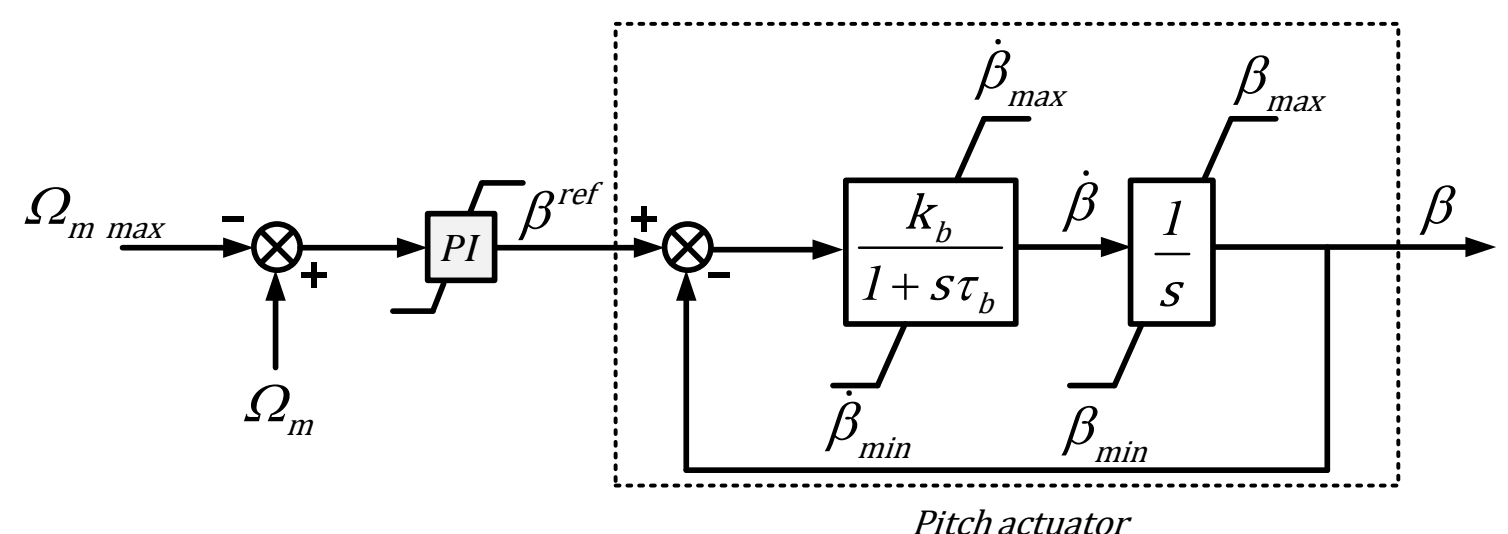

Figure 5. Wind turbine speed control.

The speed control loop will ensure that the WT $\Omega_{m \max }$ is not exceeded by acting on the pitch control system. The blade pitch angle $\beta$ is adjusted reducing or increasing $P_{m}$ until it matches $P_{l}$. Note that this control system is similar to the one used grid-tied WTs for limiting power when the wind speed is higher than rated. The only difference is that here $\Omega_{m \text { max }}$ can be achieved at any wind speed, depending on the load power value.

The pitch actuator block represents the dynamics of the pitch servo mechanism. The pitch actuator has been modeled as a first order function [23] defined by a gain parameter, $k_{b}$, and a time constant $\tau_{b}$ (see Appendix A), where the input is the error signal between the pitch reference angle and the actual 
pitch angle. The output of this block is the pitch angle rate, which must be limited to the maximum and minimum allowable pitch angle rates $\left(\dot{\beta}_{\max }, \dot{\beta}_{\min }\right)$. The actual pitch angle is then calculated by integrating the pitch angle rate and limited between the maximum and minimum allowable pitch angles $\left(\beta_{\max }, \beta_{\min }\right)$.

The WT power control (WTPC) follows $P_{m}$ by regulating the pitch angle. Figure 6a shows $P_{m}$ output achieved for two values of $\beta$, at $\Omega_{m} \max$. Starting at $P_{m 1}$, if $P_{l}$ is gradually increased, $\beta$ will be gradually decreased until the minimum pitch angle is achieved $\left(\beta=\beta_{\min }=0\right)$. When the minimum pitch angle is achieved, the speed controller output reaches saturation, as the WT cannot longer increase the power extraction from the wind by adjusting $\beta$. From this point, two different situations could be derived if load power is increased even more.

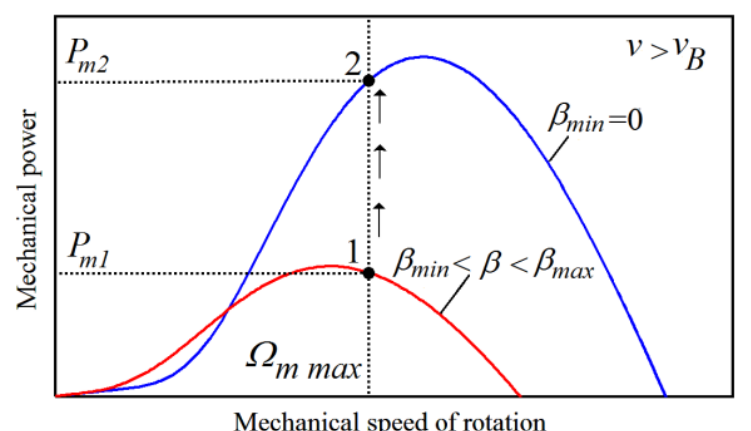

(a)

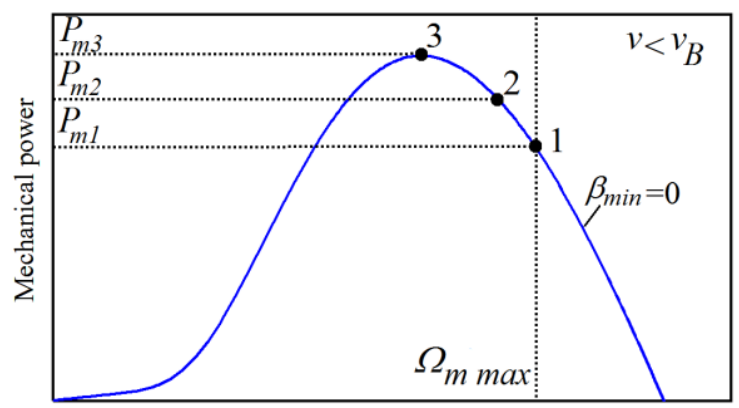

Mechanical speed of rotation

(b)

Figure 6. Wind turbine power-speed characteristic, (a) Speed regulation by adjusting the pitch angle; (b) Increasing wind turbine output by reducing rotational speed.

For $v>v_{B}$ (Figure 6a), $P_{m}$ cannot be increased any further (point 2 ), because this requires increasing $\Omega_{m}$ and the WT is already rotating at maximum speed. Therefore, the maximum power of the WT has been achieved for the incoming wind, as given by the power curve of the WT. In Figure 2, this situation is given by the segment C-D, where, for example, the intersection point of the $v=11 \mathrm{~m} / \mathrm{s}$ curve and the segment $\mathrm{C}$-D would represent the maximum power that can be supplied at that wind speed (point 2 in Figure 6a).

For $v<v_{B}$ (Figure $6 \mathrm{~b}$ ), when the minimum pitch angle is reached (point 1 ), and $P_{l}$ is higher than $P_{m}$, the turbine will decelerate. But in this case, the deceleration of the WT will produce an adjustment of $P_{m}$ until the power balance is met. Starting from a balanced power point 1 with minimum pitch angle and $\Omega_{m} \max$, if $P_{l}$ increases up to point 2, the turbine will decelerate until the new power balance is met, that is, the power-speed characteristic of the turbine will ensure that any load power can be supplied until the maximum power point is achieved in point 3 . When the maximum power point is reached, $P_{m}$ cannot be increased any more as the maximum power of the WT has been achieved for the incoming wind. Load shedding is then required to maintain the power balance. In Figure 2, this situation is given by the curve B-C, where, for example, the intersection point of the $v=9 \mathrm{~m} / \mathrm{s}$ curve and the curve B-C would represent the maximum power that can be supplied at that wind speed (point 3 in Figure 6b).

Note that the reasoning above is also valid in the case of a variation of $P_{m}$, due to a change in $v$. For example, if $v$ decreases while supplying a given load, $\Omega_{m}$ will decrease, increasing $C_{p}$ and therefore compensating the reduction in power due to a lower $v$.

\subsection{Load Shedding}

In order to assure that the maximum power that the WT can deliver (as given by the power-speed curve A-B-C-D of Figure 2) is not exceeded by the generator, leading to an unstable operation of the WT, a load regulation has to be implemented, which will be a function of $\Omega_{m}$. When the WT reaches 
the stability limit, the load regulation scheme avoids falling into instability: a reduction in $\Omega_{m}$ that will lead to a further reduction of the WT power. This load regulation scheme could be a simple load shedding mechanism or a continuous load regulation mechanism, if the load can be regulated in such way, like in pumping stations or battery charging [24].

\section{Simulation Results}

The simulation results and analysis of the proposed DVFC and WTPC are discussed in this section. A detailed simulation in PSIM $\odot$ software (UC3M, Leganés, Spain) [25] has been used for the validation, using the parameters of a 2 MW WT. The simulation workbench parameters are given in the Appendix A.

\subsection{Results With Constant Wind Speed and Variable Load}

During this test wind speed is kept constant at $11 \mathrm{~m} / \mathrm{s}$. The WT is initially running at maximum speed (2000 rpm at the generator axis) at not-load as is shows in Figure 7. The rotational speed is controlled by adjusting the pitch angle through the speed controller of Figure 5. In this scheme the pitch actuator rate has been limited to $10^{\circ} / \mathrm{s}$ as a realistic value for simulation.

At $\mathrm{t}=5 \mathrm{~s}$, a $1 \mathrm{MW}$ load is applied to the generator. In order to supply such load the blade pitch angle is decreased, increasing $P_{m}$ while maintaining maximum rotational speed (see Figure 7). Following, at $\mathrm{t}=10 \mathrm{~s}$, the load is increased up to $2 \mathrm{MW}$ and the blades are now pitched to the optimum position $(\beta=0)$ to increase $P_{m}$. At this point, the turbine is not supplying enough power to the load, producing a reduction of the rotational speed up to $1770 \mathrm{rpm}$. This reduction of the speed in turn produces an increase of $C_{p}$, which allows for supplying the load power.

Finally, at $t=15 \mathrm{~s}$, a reactive load is connected. It is shown in Figure 8. The reactive power is automatically supplied by the generator by adjusting the d-axis rotor current and does not require any adjustment by the WTPC as is observed in Figure 7.
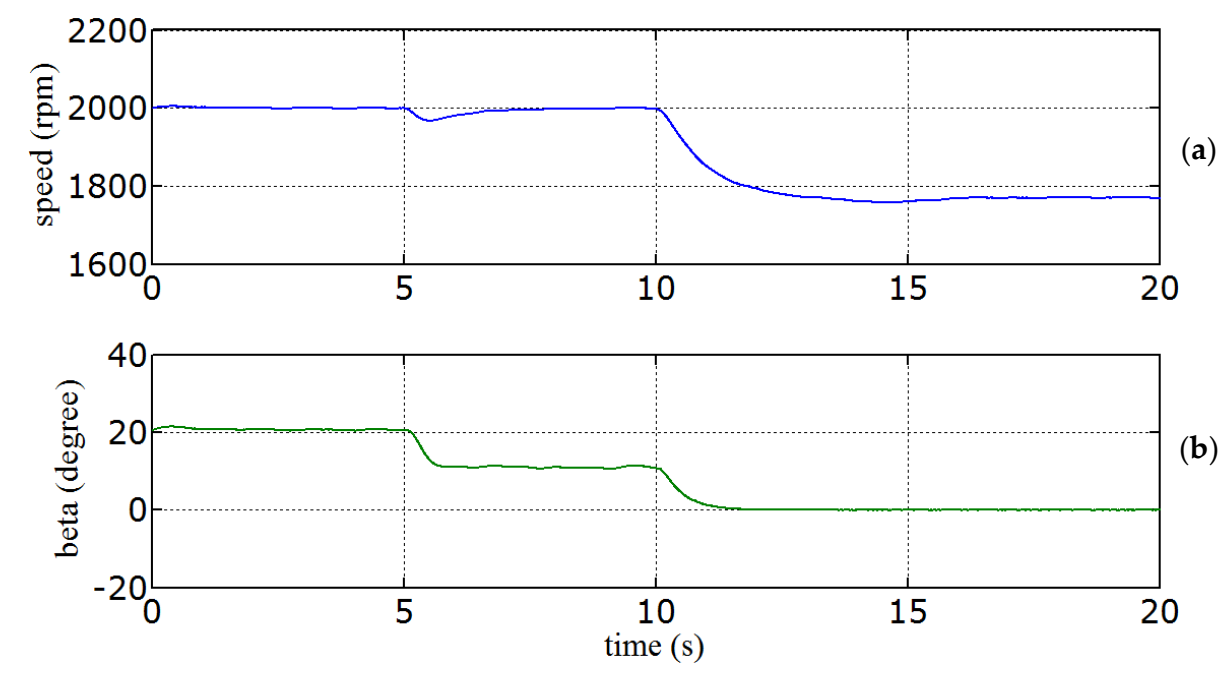

Figure 7. Operation at variable load and constant wind speed [(a) rotational speed; (b) pitch angle]. 

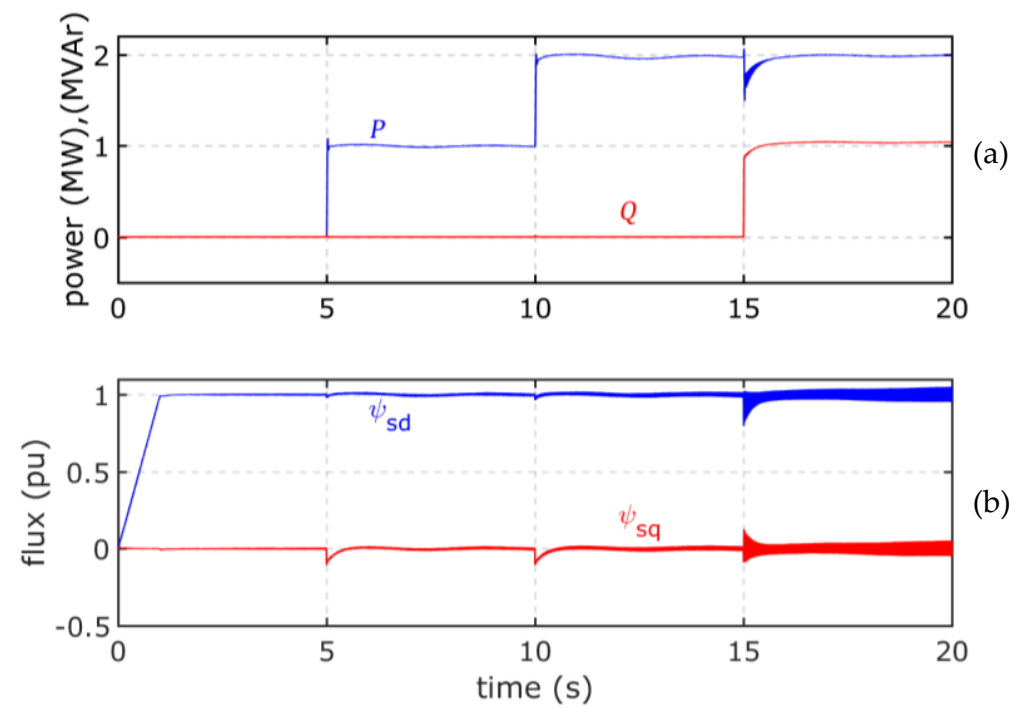

Figure 8. Operation at variable load and constant wind seep [(a) load power; (b) stator flux].

Figure 8 shows the load active and reactive power and the DFIG stator flux. Stator flux is presented in per unit because it is easier to understand regarding the proposed control system. Base value is given in the appendix. This figure shows the capability of the DVFC to control the stator flux as required, that is, maintaining constant $d$-axis flux equal to nominal, which in turn means maintaining nearly constant voltage, and maintaining constant q-axis flux equal to zero, which in turn means maintaining constant frequency. It has to be remarked that frequency control does not require frequency measurement, but the stator flux in the reference synchronous axis. Figure 8 also shows that the stator flux, and therefore the stator voltage, is gradually increased from zero to rated at the beginning of the simulation for starting-up (from 0 until $1 \mathrm{~s}$ ). Figure 9 shows a zoom-in of the generated instantaneous voltage in one phase from 0 to $1.5 \mathrm{~s}$.

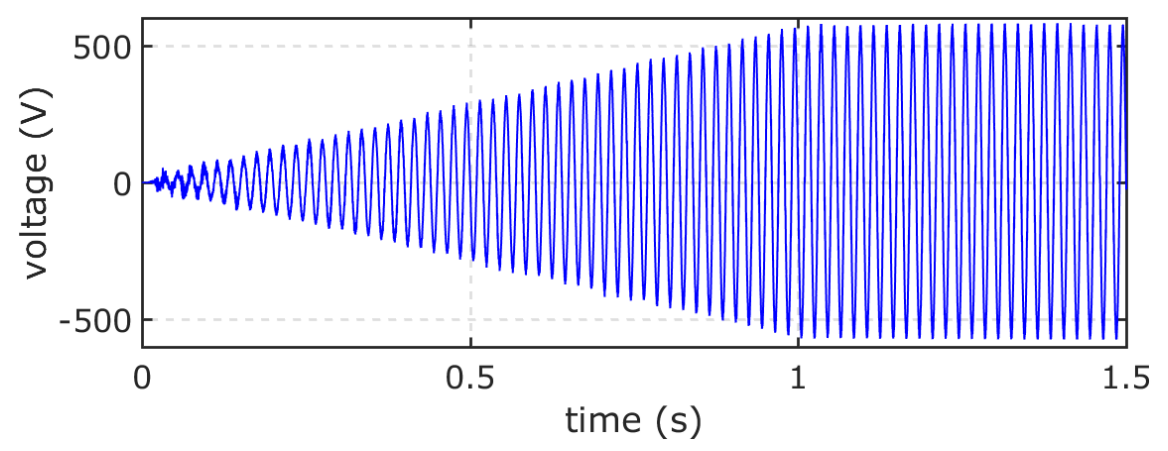

Figure 9. Voltage generation during start-up.

On the other hand, Figure 10 shows a zoom of the instantaneous load voltages and currents around the active power step. As stated before, voltage is maintained nearly constant by the DVFC. Also, note that frequency is not affected by the rotational speed change at $t=10 \mathrm{~s}$ (see Figure 7), due to the fast electrical magnitudes control in opposition to the slower mechanical magnitudes control, showing a total decoupling between both control system. 

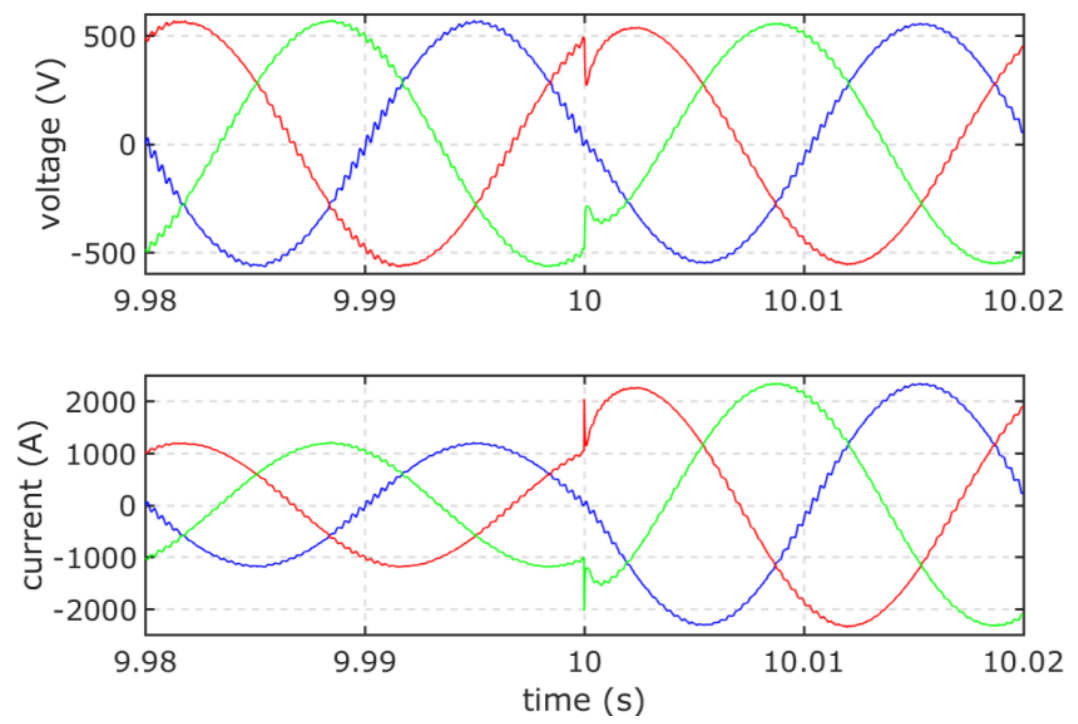

Figure 10. Operation at variable load and constant wind speed: instantaneous load voltage and current under active power step (phase a-red; phase b-green; phase c-blue).

Finally, Figure 11 shows a zoom-in of the instantaneous load voltage and current around $t=15 \mathrm{~s}$ (when a reactive load is applied to generator). This figure shows that the reactive load produces a transient voltage drop, but this disturbance is quickly compensated by the proposed voltage and frequency control system.
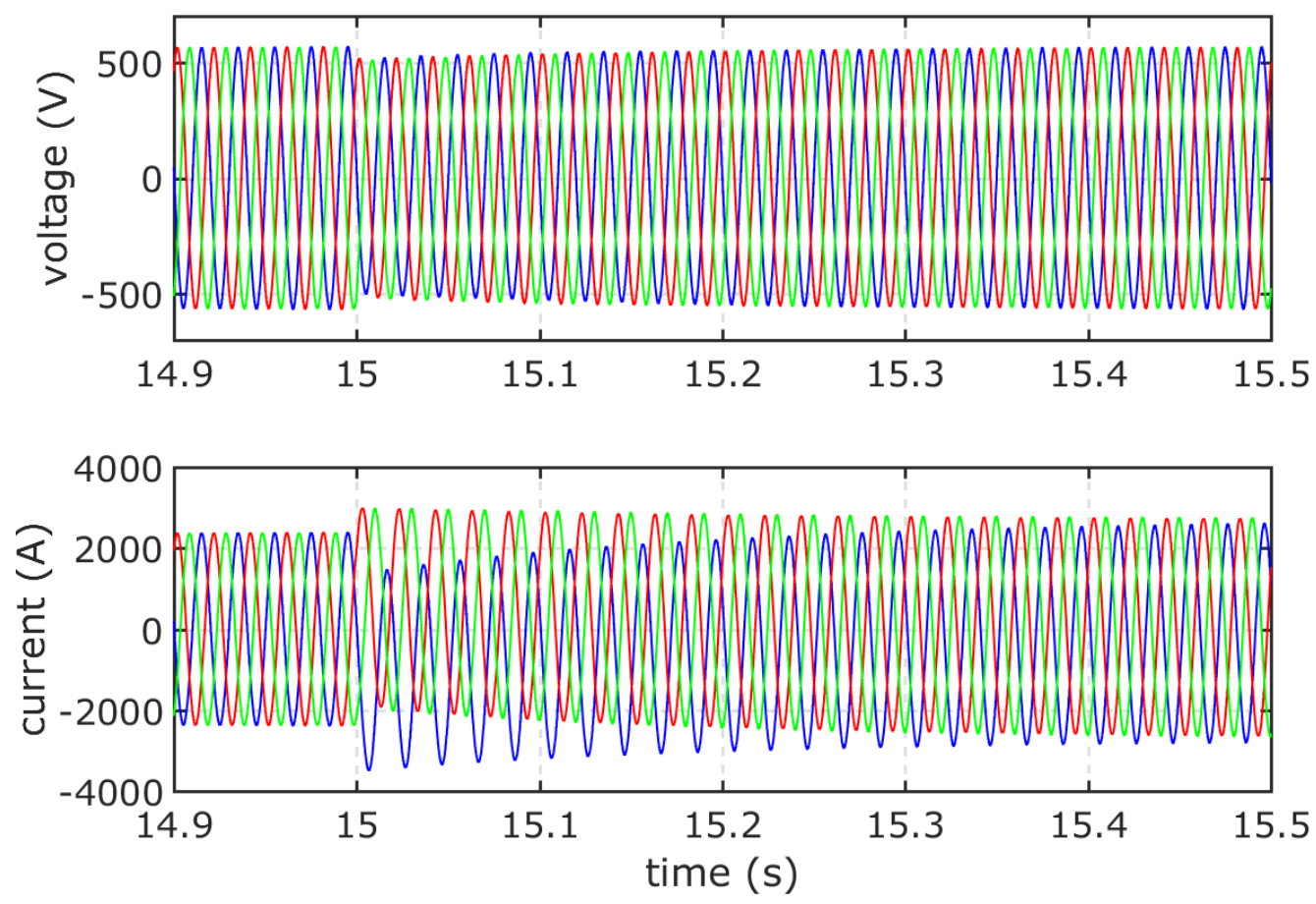

Figure 11. Operation at variable load and constant wind speed: instantaneous load voltage and current under reactive power step (phase a-red; phase b-green; phase c-blue). 


\subsection{Results with Variable Wind Speed and Constant Load}

In this simulation case, wind speed changes from $11 \mathrm{~m} / \mathrm{s}$ to $15 \mathrm{~m} / \mathrm{s}$ at $\mathrm{t}=4 \mathrm{~s}$, while supplying a constant 2 MW load. The test starts with the ending conditions of the previous one, when the WT is supplying the rated load at a rotational speed bellow maximum (1770 rpm approx.), and the pitch angle is adjusted to zero. Then, wind speed increases, producing an excess of power and increasing the rotational speed (see Figure 12). Nevertheless, the increase of the rotational speed (which produces a $C_{p}$ reduction) is not enough for reducing the mechanical power, in order to balance the mechanical and the load power. So, when maximum rotational speed is achieved the pitch angle increases to reduce the WT power while maintaining maximum speed, which means that the mechanical power generated by the WT equals the power demanded by the load.
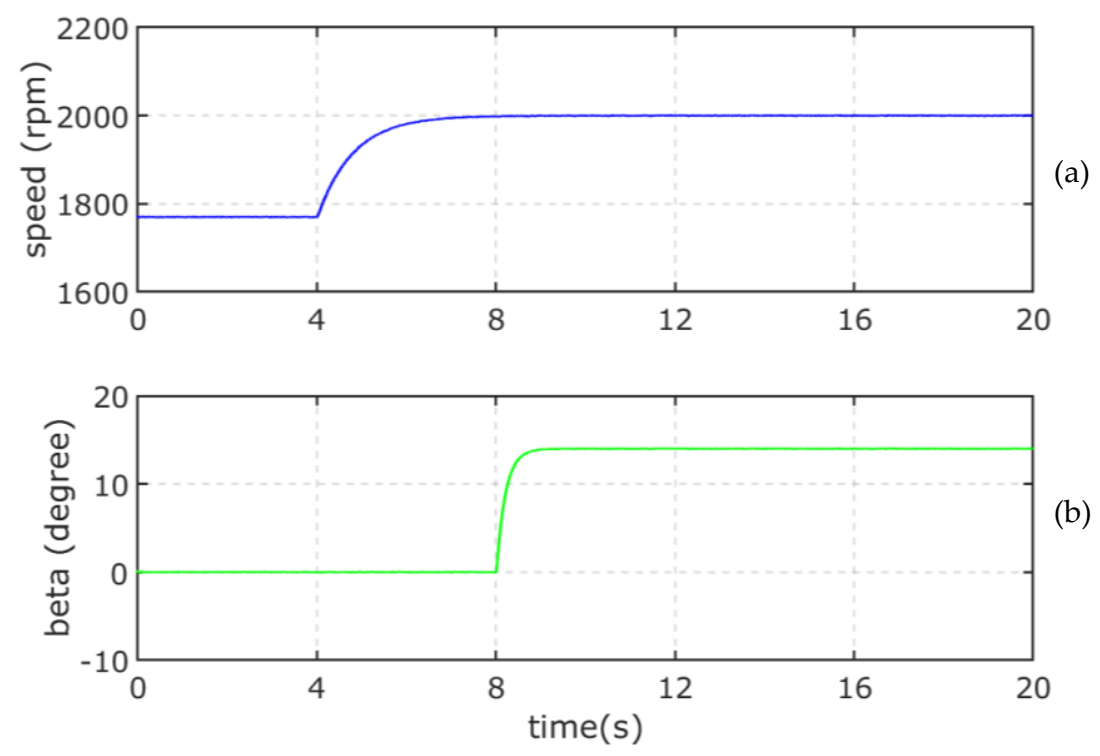

Figure 12. Operation at constant load and variable wind speed [(a) rotational speed; (b) pitch angle].

In this case, the electrical variables do not show any interesting behavior because the increase of wind speed mainly disturbs the mechanical system, and the small disturbance in the electrical system is quickly compensated for by the DVFC. Therefore, the load power is kept constant as the DVFC is able to maintain constant voltage and frequency during this test.

\subsection{Results Under a Change in the Reference Signals with Constant Wind Speed and Constant Load}

In this simulation case, wind speed and load are maintained constant, but a change is applied to the reference signals, that is, a change is applied to the reference frequency and also to the reference flux magnitude. Although this case does not represent any operational case, it is interesting for demonstrating the capabilities of the proposed control system.

This test starts with the ending conditions of the previous one. The WT is supplying rated power to a resistive load. Wind speed is $15 \mathrm{~m} / \mathrm{s}$ and rotational speed is maximum (2000 rpm) with $\beta=14^{\circ}$ approx. It is important to remark that although the resistive load is not affected by the frequency, the change in the flux frequency will produce a proportional increment of the voltage, which in turn will produce a change in the load power, proportional to the square of the voltage. 
At $\mathrm{t}=0.5 \mathrm{~s}$, a frequency step from $50 \mathrm{~Hz}$ to $55 \mathrm{~Hz}$ is applied. This new frequency is quickly adjusted by the DVFC, as shown in Figure 13. This frequency adjustment produces only a small disturbance in the quadrature component of the stator flux, while no disturbance can be appreciated in the direct component of the stator flux. As a result, while maintaining constant rotational speed, the voltage frequency is increased by decreasing the frequency of the impressed rotor currents, as can be seen in Figure 14.
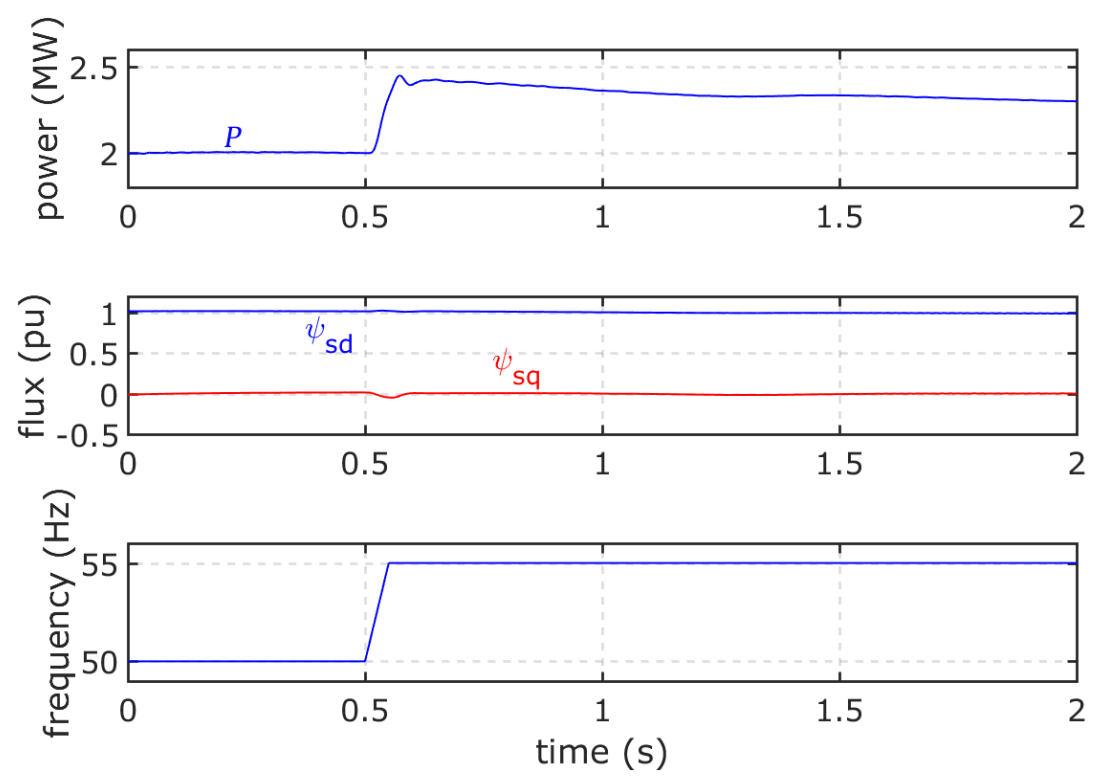

Figure 13. Response to a frequency step at constant wind speed and load.

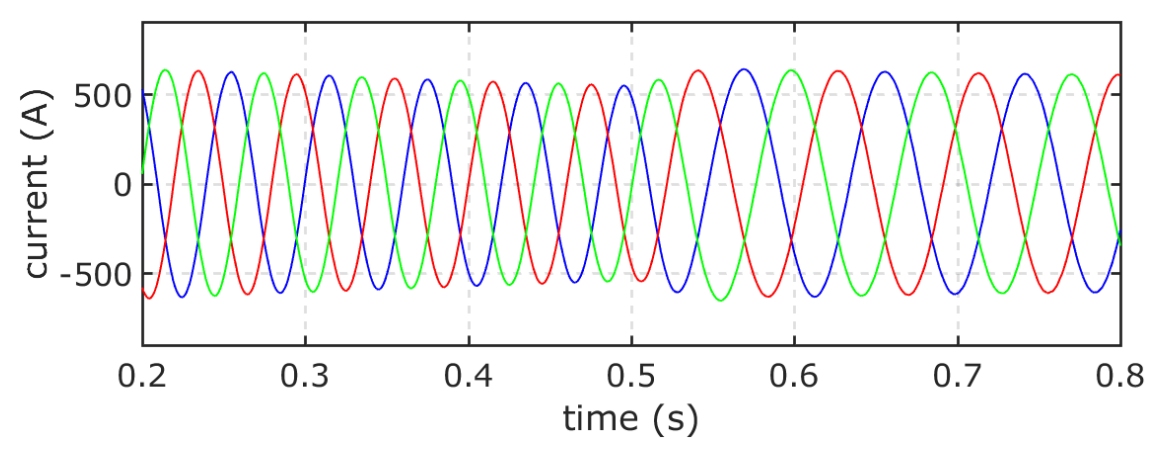

Figure 14. Rotor currents response to a frequency step at constant wind speed and load (phase a-red; phase b-green; phase c-blue).

In the following test the stator flux magnitude is increased by $10 \%$. Figure 15 shows the simulation results. The increase of the stator flux produces a proportional increase of the generated stator voltage. Which, on the other hand, produces an increment of the power demanded by the load (with a resistive load, power is proportional to the square of the voltage magnitude). Figure 16 shows the resulting stator voltage change. 

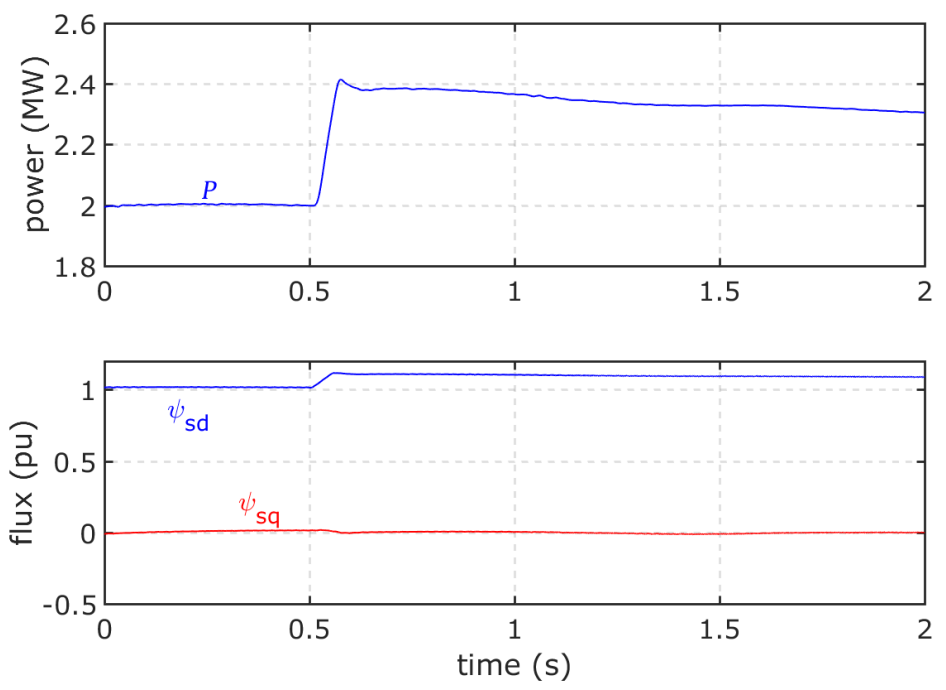

Figure 15. Response to a stator flux step at constant wind speed and load.

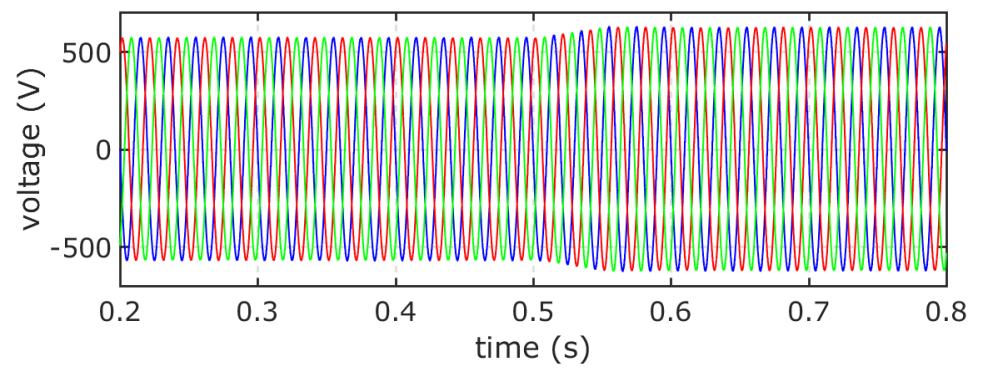

Figure 16. Stator voltage response to a stator flux step at constant wind speed and load (phase a-red; phase b-green; phase c-blue).

\section{Conclusions}

This paper has presented a novel control scheme for the stand-alone operation of a variable speed wind turbine with DFIG. For such purpose the DFIG voltage and frequency, and also the WT power, have to be controlled in order to supply just the power demanded by the load.

The voltage and frequency control (DVFC) is based on the stator flux orientation along a synchronous reference axis. The rotational speed of this synchronous reference axis is generated by control and therefore is not subjected to any measurement disturbance. The magnitude and angular frequency of the stator flux is controlled through the rotor current components by the rotor voltages imposed by the RSC. With constant stator flux magnitude and frequency, the stator voltage is only subjected to a small disturbance due to the voltage drop in the stator resistance, and therefore a voltage regulator is not required.

On the other hand, the power drawn from the WT (WTPC) is controlled by means of a speed control loop relying on the pitch control of the WT. By controlling rotational speed, the power drawn from the WT is maintained equal to the generator power, and in turn to the load power.

The proposed control scheme has been validated in a simulated workbench. Simulation results show the response of proposed control system under varying load, wind speed and reference signals, demonstrating the capability of the proposed control system to maintain constant voltage and frequency under varying loads and wind velocities with an excellent dynamic response.

Acknowledgments: This work has been supported by the I+D program for Research Groups of the Autonomous Community of Madrid under ref. S2013/ICE-2933.

Author Contributions: The authors contributed equally to this work. 
Conflicts of Interest: The authors declare no conflict of interest.

\section{Nomenclature}

$\begin{array}{ll}\Theta & \text { encoder angle } \\ \theta_{s}, \theta_{r}, \theta_{s p} & \text { stator, rotor, and slip voltage angle } \\ \text { Subscripts } & \\ d, q & \text { synchronous dq axis } \\ s, r & \text { stator, rotor } \\ g, l, m & \text { generator, load, wind turbine } \\ B & \text { base values } \\ \text { Superscripts } & \\ \text { ref } & \text { reference value } \\ \text { Acronyms } & \\ \text { VSC } & \text { Voltage-sourced converter } \\ \text { LCC } & \text { Line-commutated converter } \\ \text { HVdc } & \text { High-voltage direct current } \\ \text { WT } & \text { Wind turbine } \\ \text { DFIG } & \text { Doubly-fed induction generator } \\ \text { DVFC } & \text { Direct voltage and frequency control } \\ \text { WTPC } & \text { Wind turbine power control } \\ \text { LSC } & \text { Line side converter } \\ \text { RSC } & \text { Rotor side converter }\end{array}$

Appendix A

Wind turbine parameter

Rated power $P_{n}=2.0 \mathrm{MW}$

Maximum rotational speed $n_{m \text { max }}=20 \mathrm{rpm}$

Base wind speed $v_{B}=10.5 \mathrm{~m} / \mathrm{s}$

Rated wind speed $v_{n}=12 \mathrm{~m} / \mathrm{s}$

Rotor radius $R=38 \mathrm{~m}$

$\mathrm{C}_{\text {pmax }}=0.48$

$\lambda_{B}=8.1$

$\beta$ range $0^{\circ}-45^{\circ}$

$\beta$ rate range \pm 10 degrees $/ \mathrm{s}$

Pitch servo gain, $k_{b}=2$

Pitch servo time constant, $\tau_{b}=0.2 \mathrm{~s}$

Gear ratio $n_{r} / n_{m}=100$

Inertia $J=7 \times 10^{4} \mathrm{~kg} \cdot \mathrm{m}^{2}$

Friction coefficient $D=0.06 \mathrm{Nm} \cdot \mathrm{s}$

Double fed induction generator

Rated stator power $P_{n s}=2.25 \mathrm{MVA}$

$f=50 \mathrm{~Hz}$

Synchronous speed $n_{S}=1500 \mathrm{rpm}$ (4 poles)

Rated stator voltage $U_{g B}=690 \mathrm{~V}$

Rotor blocked rotor voltage $U_{r 0}=2070 \mathrm{~V}$

Base stator flux $\Psi_{s B}=85.8 \mathrm{~V} \cdot \mathrm{s}$

$\mathrm{Ns} / \mathrm{Nr}=0.333$

Stator resistance $R_{S}=2.48 \mathrm{~m} \Omega$

Rotor resistance (referred to stator) $R_{r}=2.72 \mathrm{~m} \Omega$

Stator leakage inductance $L_{\sigma s}=86.5 \mu \mathrm{H}$

Rotor leakage inductance $L_{\sigma r}$ (referred to stator) $=86.5 \mu \mathrm{H}$

Magnetizing inductance $L_{m}=2.50 \mathrm{mH}$

\section{References}

1. Tsili, M.; Papathanassiou, S. A review of grid code technical requirements for wind farms. IET Renew. Power Gener. 2009, 3, 308-332. [CrossRef] 
2. Rocabert, J.; Luna, A.; Blaabjerg, F.; Rodriguez, P. Control of power converters in ac microgrids. IEEE Trans. Power Electron. 2012, 27, 4734-4749. [CrossRef]

3. Ribeiro, L.; Saavedra, O.; Lima, S.; Matos, J.; Bonan, G. Making isolated renewable energy systems more reliable. Renew. Energy 2012, 45, 221-231. [CrossRef]

4. Jiayi, H.; Chuanwen, J.; Rong, X. A review on distributed energy resources and MicroGrid. Renew. Sustain. Energy Rev. 2008, 12, 2472-2483. [CrossRef]

5. Xiang, D.; Ran, L.; Bumby, J.R.; Tavner, P.J.; Yang, S. Coordinated control of an HVDC link and doubly fed induction generators in a large offshore wind farm. IEEE Trans. Power Deliv. 2006, 21, 463-471. [CrossRef]

6. Erlich, I.; Feltes, C.; Shewarega, F.Y. Enhanced voltage drop control by VSC-HVDC systems for improving wind farm fault Ridethrough capability. IEEE Trans. Power Deliv. 2014, 29, 378-385. [CrossRef]

7. Lujano-Rojas, J.M.; Monteiro, C.; Dufo-López, R.; Bernal-Agustín, J. Optimum load management strategy for wind/diesel/battery hybrid power systems. Renew. Energy 2012, 44, 288-295. [CrossRef]

8. Kanellos, F.D.; Hatziargyriou, N.D. Control of Variable Speed Wind Turbines in Islanded Mode of Operation. IEEE Trans. Energy Convers. 2008, 23, 535-543. [CrossRef]

9. Paiva, J.E.; Carvalho, A.S. Controllable hybrid power system based on renewable energy sources for modern electrical grids. Renew. Energy 2013, 53, 271-279. [CrossRef]

10. Ackermann, T. Wind Power in Power Systems; John Wiley \& Sons: Chichester, UK, 2005; pp. 480-504.

11. Li, H.; Chen, Z. Overview of different wind generator systems and their comparisons. IET Renew. Power Gener. 2008, 2, 123-138. [CrossRef]

12. $\mathrm{Xu}, \mathrm{L} . ;$ Cartwright, P. Direct active and reactive power control of DFIG for wind energy generation. IEEE Trans. Energy Convers. 2006, 21, 750-758. [CrossRef]

13. Müller, S.; Deicke, M.; De Donker, R.W. Doubly Fed Induction Generator Systems for Wind Turbines. IEEE Ind. Appl. Mag. 2002, 8, 26-33. [CrossRef]

14. Peña, R.; Cardenas, R.; Asher, G. Overview of control systems for the operation of DFIGs in wind energy applications. In Proceedings of the 39th Annual Conference of the IEEE Industrial Electronics Society, IECON 2013, Vienna, Austria, 10-13 November 2013; pp. 88-95.

15. Peña, R.; Clare, J.C.; Asher, G.M. A doubly fed induction generator using back to back PWM converters supplying an isolated load from a variable speed wind turbine. Proc. IEE Electr. Power Appl. 1996, 143, 380-387. [CrossRef]

16. Cárdenas, R.; Peña, R.; Asher, G.; Clare, J. MRAS observer for sensorless control of standalone doubly fed induction generators. IEEE Trans. Energy Convers. 2005, 20, 710-718. [CrossRef]

17. Ataji, A.B.; Miura, Y.; Ise, T.; Tanaka, H. Direct Voltage Control with Slip Angle Estimation to Extend the Range of Supported Asymmetric Loads for Stand-Alone DFIG. IEEE Trans. Power Electron. 2016, 31, 1015-1025. [CrossRef]

18. Abdoune, F.; Aouzellag, D.; Ghedamsi, K. Terminal voltage build-up and control of a DFIG based stand-alone wind energy conversion system. Renew. Energy 2016, 97, 468-480. [CrossRef]

19. Shukla, R.D.; Tripathi, R.K. A novel voltage and frequency controller for standalone DFIG based Wind Energy Conversion System. Renew. Sustain. Energy Rev. 2014, 37, 69-89. [CrossRef]

20. Iwanski, G.; Koczara, W. Autonomous power system for island or grid-connected wind turbines in distributed generation. Eur. Trans. Electr. Power 2008, 18, 658-673. [CrossRef]

21. Touaiti, B.; Azza, H.B.; Jemli, M. Direct voltage control of stand-alone DFIG in wind energy applications. In Proceedings of the IEEE 16th International Conference on Sciences and Techniques of Automatic Control and Computer Engineering (STA), Monastir, Tunisia, 21-23 December 2015; pp. 672-677.

22. Abad, G.; López, J.; Rodríguez, M.A.; Marroyo, L.; Iwanski, G. Doubly Fed Induction Machine: Modeling and Control for Wind Energy Generation; IEEE Press and John Wiley \& Sons: Hoboken, NJ, USA, 2011.

23. Akhmatov, V. Variable-speed wind turbines with doubly-fed induction generator. Part I: Modeling in dynamic simulation tools. Wind Eng. 2002, 26, 85-108. [CrossRef]

24. Moura, S.P.; de Alemeida, A.T. The role of demand-side management in the grid integration of wind power. Appl. Energy J. 2010, 87, 2581-2588. [CrossRef]

25. PSIM Accelerates Your Pace of Innovation. Available online: https:/ / powersimtech.com (accessed on 27 November 2017).

(C) 2017 by the authors. Licensee MDPI, Basel, Switzerland. This article is an open access article distributed under the terms and conditions of the Creative Commons Attribution (CC BY) license (http:/ / creativecommons.org/licenses/by/4.0/). 